\title{
Significance of Respiratory Sinus Arrhythmia in Human Health and Disease
}

\author{
Melvin F Simoyi* \\ Department of Biology, College of arts and science, Heritage University, 3240 Fort Rd, Toppenish, WA 98948, USA
}

*Corresponding author: Melvin F Simoyi, Department of Biology, College of arts and science, Heritage University, 3240 Fort Rd,

Toppenish, WA 98948, USA

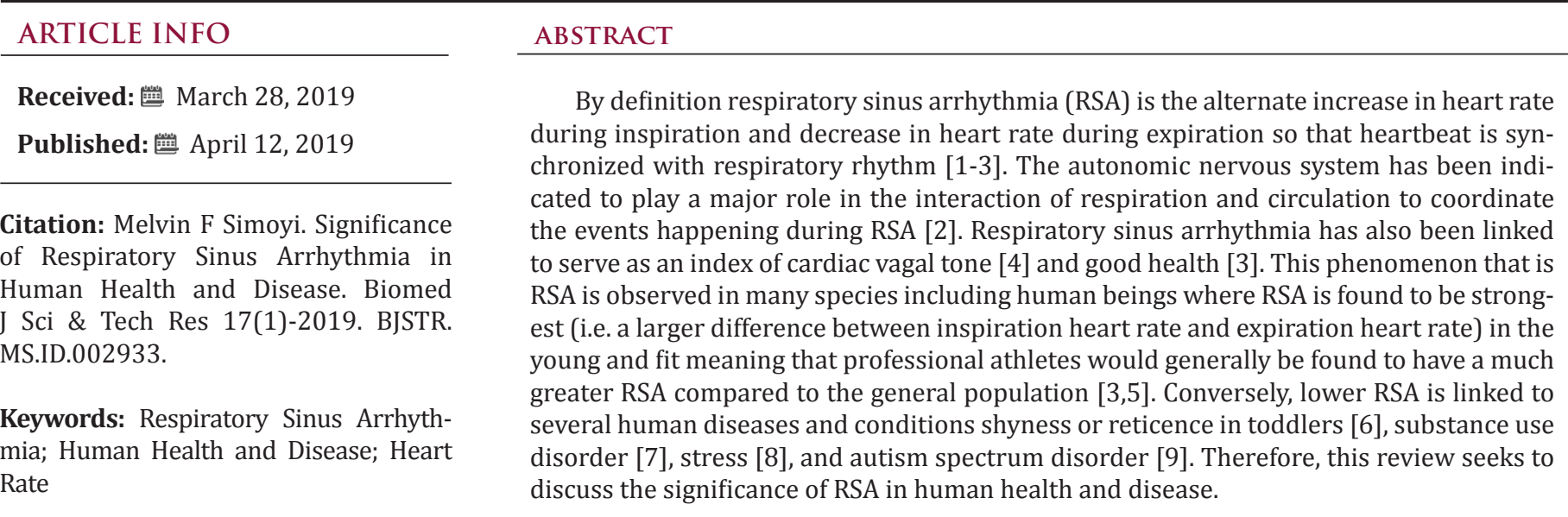

\section{Introduction}

It is well documented that RSA is widely observed among vertebrates throughout their evolution which suggests that it may have an intrinsic physiological role $[1,2,4,10]$. Early studies have shown that the physiological role of RSA is to coordinate ventilation of the lungs with blood perfusion of the lungs so as to maximize the exchange of gases between alveoli and blood $[2,10]$. Thus during inspiration when alveoli oxygen content is highest, heart rate is fastest to ensure that the most blood is pumped to the lungs for maximum efficiency in gas exchange. The reverse is true for expiration when alveoli carbon dioxide content is relatively higher with lower oxygen content where heart rate is slowest resulting in less blood being pumped to the lungs. Respiratory sinus arrhythmia has even been used as an index of toddler parasympathetic arousal in a study investigating fathering and how it influences toddler emotion regulation [11]. Without question, RSA has an immense physiological role to play in the human body. The entire organism depends upon a constant supply of oxygen and nutrients and a constant removal of metabolic waste and carbon dioxide to and from all cells for the organism to function properly. Thus the cardiovascular system plays a pivotal role in organisms. It is therefore critical for the heart to function optimally for the wellbeing of an organism [12] and is exactly the reason why HR is precisely controlled by several mechanism in the body [13]. Respiratory sinus arrhythmia is front and center as part of these mechanisms that modulate or influence HR. It goes without saying and comes as no surprise that RSA itself involves a system that furnishes the body with oxygen and removes carbon dioxide, namely the respiratory system, which is an attempt by the organism to ensure strict regulation of these gases. Indeed, RSA has been linked to the efficiency by which pulmonary gas exchange occurs in healthy individuals where ventilation is synchronized with perfusion in each respiratory cycle [14]. Consequently, it is therefore important to understand why RSA happens and the various mechanism involved in RSA.

Not only is RSA associated with and is used to explain phenomena in healthy human beings including superior physical ability, RSA has been associated with various human conditions and is used to diagnose disease in humans. Shyness is a human behavioral trait or disposition that is marked by fear of or guardedness within new social settings [15]. Respiratory sinus arrhythmia measured at rest (basal RSA) is thought to signify a temperamental capacity for selfregulation of emotional arousal through control of vagal activity and the effects of the parasympathetic nervous system [16]. Based on this observation, Grady and Callan, in a study of shy toddlers 
and their exhibition of reticence in social contexts, reported that high basal RSA was positively correlated with bold approach with an unfamiliar female examiner by shy toddlers [6]. This means that low basal RSA is associated with being reserved in shy toddlers indicating that toddlers with low basal RSA will not thrive in new social settings such as daycare, kindergarten later in life, and so forth eventually affecting their effectiveness in social settings as adults or their intellect for that matter. The research on shyness in toddlers [6] is related to substance use disorder in that emotional and self-regulatory processes are disrupted in people with this disorder as a result of the dysfunction of physiological regulation systems [7]. Price and Crowell investigated whether RSA could be used as a psychophysiological index of emotional regulation which could furnish information useful in the treatment of substance use disorder as well as in its recovery process. They indeed found that RSA may be used as an index of self-regulatory capacity in the 4 mindfulness-based intervention studies they reviewed. In 2 of the studies that had substance using samples, Price and Crowell [7] showed that pre-post RSA was elevated and was related to improved substance use outcomes. Three of the 4 studies were randomized control trials of which 2 studies reported significant increases in RSA in the experimental condition compared to the comparison condition. The diversity of situations and conditions in which RSA may be applied yielding relevant and useful data is astounding.

Since RSA is used as a peripheral marker of cardiac-linked parasympathetic regulation as well as an index for emotion regulation, it follows that the parasympathetic modulation of the heart as signified by RSA is linked to a complex system in which the nervous system regulates emotional and cognitive processing [8]. It is with this understanding that Tonhajzerova and coworkers [8] concluded that high resting or basal RSA may lead to greater withdrawal during stressors and subsequently better recovery which may represent a flexible and adaptive physiological response system to a challenge. On the other hand, low resting RSA together with poor reactivity to stress may be indicative of maladaptive regulatory mechanisms; Tonhajzerova and coworkers [8] further extrapolated. The increases in RSA were different depending on the stressor which suggests that this may have important implications for several mental disorders such as depression and anxiety [8]. Another study [9] also utilized basal RSA and RSA reactivity to predict restricted repetitive behaviors in children with autism spectrum disorder and found a positive correlation between severity of these restricted repetitive behaviors and RSA. There seems to be no end to the applications for which RSA is useful. There is a multitude of studies describing what RSA is and how it is applied in studies with healthy individuals, athletes, and also how RSA is applied in studies of various conditions and disease states yet it seems we are just barely scratching the surface when considering the potential wealth of information we can attain from studies of RSA. The various applications for RSA in and of themselves are testament to the importance of RSA. More studies looking at other physiological factors that may affect RSA in healthy subjects will continue to further our understanding of this phenomenon.

\section{References}

1. Hayano J, Yasuma F (2003) Hypothesis: respiratory sinus arrhythmia is an intrinsic resting function of cardiopulmonary system. Cardiovasc Res 58(1): 1-9.

2. Yasuma F, Hayano J (2004) Respiratory sinus arrhythmia: why does the heartbeat synchronize with respiratory rhythm? Chest 125(2): 683-690.

3. Ben-Tal A, Shamailov SS, Paton JF (2012) Evaluating the physiological significance of respiratory sinus arrhythmia: looking beyond ventilationperfusion efficiency. J Physiol 590(8): 1989-2008.

4. Grossman P, Taylor EW (2007) Toward understanding respiratory sinus arrhythmia: relations to cardiac vagal tone, evolution and biobehavioral functions. Biol Psychol 74: 263-285.

5. Dixon EM, Kamath MV, McCartney N, Fallen EL (1992) Neural regulation of heart rate variability in endurance athletes and sedentary controls. Cardiovasc Res 26(7): 713-719.

6. Grady JS, Callan D (2019) Shy toddlers act bold: The roles of respiratory sinus arrhythmia and parent emotion language. Infant Behav Dev 55(3): 32-37.

7. Price CJ, Crowell SE (2016) Respiratory sinus arrhythmia as a potential measure in substance use treatment--outcome studies. Addiction 111(4): 615-625.

8. Tonhajzerova I, Mestanik M, Mestanikova A, Jurko A (2016) Respiratory sinus arrhythmia as a non-invasive index of 'brain-heart' interaction in stress. Indian J Med Res 144(6): 815-822.

9. Condy EE, Scarpa A, Friedman BH (2017) Respiratory Sinus Arrhythmia Predicts Restricted Repetitive Behavior Severity. J Autism Dev Disord 47(9): 2795-2804.

10. Hayano J, Yasuma F, Okada A, Mukai S, Fujinami T (1996) Respiratory sinus arrhythmia. A phenomenon improving pulmonary gas exchange and circulatory efficiency. Circulation 94: 842-847.

11. Richardson PA, Bocknek EL, McGoron L, Trentacosta CJ Dev Psychobiol (2019) Fathering across contexts: The moderating role of respiratory sinus arrhythmia in predicting toddler emotion regulation.

12. Ben-Tal A, Shamailova SS, Paton JFR (2014) Central regulation of heart rate and the appearance of Respiratory Sinus Arrhythmia: new insights from mathematical modeling. Math Biosci 255(9): 71-82.

13. Spyer KM (1982) Central nervous integration of cardiovascular control. Journal of Experimental Biology 100(10): 109-128.

14. Giardino ND, Glenny RW, Borson S, Chan L (2003) Respiratory sinus arrhythmia is associated with efficiency of pulmonary gas exchange in healthy humans. Am J Physiol Heart Circ Physiol 284(1): H1585-H1591.

15. Coplan RJ, Rubin KH (2010) Social withdrawal and shyness in childhood: History, theories, definitions, and assessments. In Rubin KH, Coplan RJ (Eds.), PsycNet, New York, USA p. 3-20.

16. Porges SW (2007) The polyvagal perspective. Biological Psychology 74(2): 116-143. 
ISSN: 2574-1241

DOI: 10.26717/BJSTR.2019.17.002933

Melvin F Simoyi. Biomed J Sci \& Tech Res

(c) (i) This work is licensed under Creative

Submission Link: https://biomedres.us/submit-manuscript.php

$\begin{array}{ll}\text { BIOMEDICAL } & \text { Assets of Publishing with us } \\ \text { RESEARCHES } & \text { - Global archiving of articles } \\ \text { - Immediate, unrestricted online access } & \text { - Rigorous Peer Review Process } \\ & \text { - Authors Retain Copyrights }\end{array}$

